\title{
Klippel-Feil Syndrome Accompanied by Pulmonary Artery Sling
}

\author{
Yoshiyuki Kawano, Akira Tamura, Yusei Abe and Junichi Kadota
}

Key words: Klippel-Feil syndrome, pulmonary artery sling

\section{(DOI: 10.2169/internalmedicine.47.0727)}

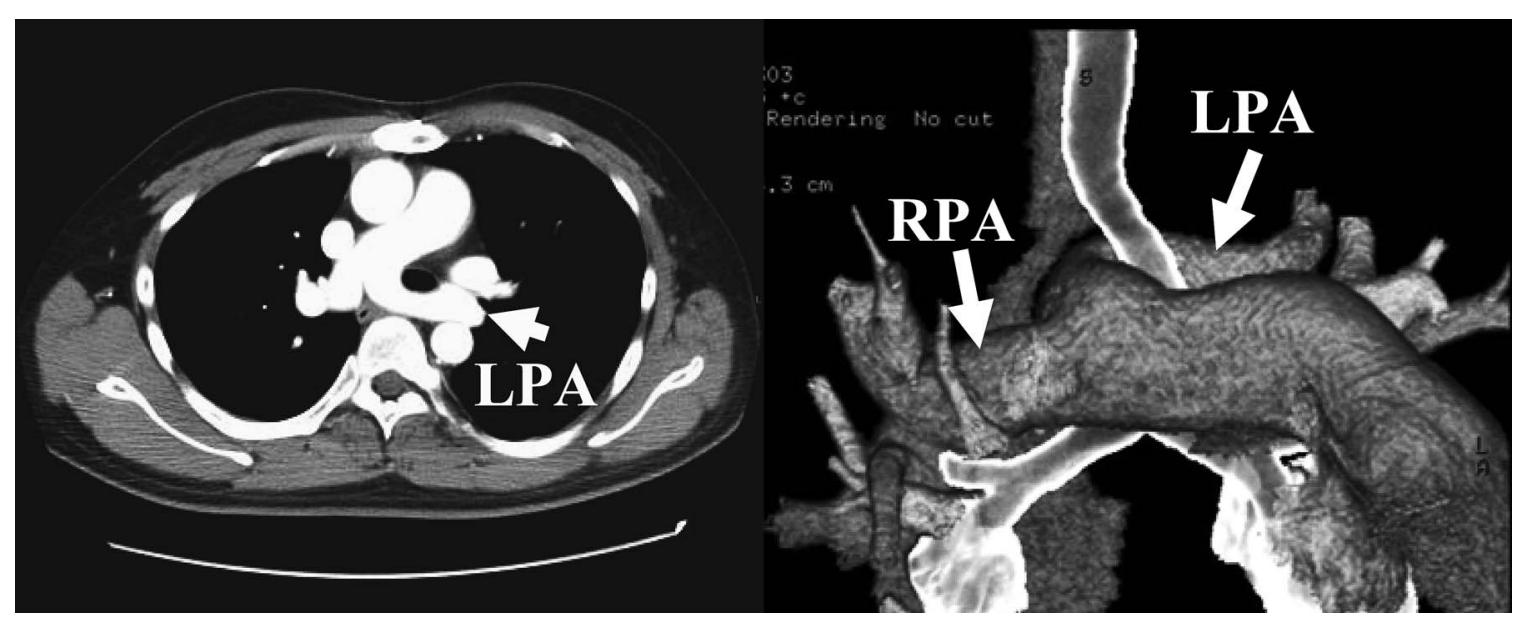

Picture 1. Multislice computed tomograms show that the left pulmonary artery originates from the posterior aspect of the right pulmonary artery and passes rightward around the trachea and between the lower portion of the trachea and esophagus. RPA=right pulmonary artery, LPA=left pulmonary artery.

A 27-year-old man was diagnosed as Klippel-Feil syndrome accompanied by a ruptured aneurysm of the noncoronary sinus of Valsalva and underwent a patch closure for the ruptured aneurysm (1). Multislice computed tomography performed before the operation showed that the left pulmonary artery originated from the posterior aspect of the right pulmonary artery and passed rightward around the trachea and between the lower portion of the trachea and esophagus (Picture 1). Since he did not have any symptoms caused by compression of the trachea and esophagus by the left pulmonary artery, an operation for this congenital anomaly was not performed. To the best of our knowledge, this is the first case report describing a patient with Klippel-Feil syndrome accompanied by pulmonary artery sling.

\section{References}

1. Kawano Y, Tamura A, Kadota J. Klippel-Feil syndrome accompanied by an aneurysm of the non-coronary sinus of Valsalva. Intern
Med 45: 1191-1192, 2006.

The Second Department of Internal Medicine, Faculty of Medicine, Oita University, Yufu Received for publication November 5, 2007; Accepted for publication November 8, 2007 Correspondence to Yoshiyuki Kawano, yoshi@med.oita-u.ac.jp

(C) 2008 The Japanese Society of Internal Medicine Journal Website: http://www.naika.or.jp/imindex.html 